\section{Evolution and us}

\section{John Beatty}

\section{Philosophy, Evolution and Human}

Nature.

By Florian von Schilcher and Neil

Tennant.

Routledge \& Kegan Paul: 1984. Pp.283.

£16.95, \$29.95.

THIS is a thought-provoking book - the result of a brainstorming collaboration between a philosopher (Tennant) and a behavioural geneticist and evolutionist (von Schilcher). The authors are mainly concerned with the ramifications of adaptationist accounts of human nature. They succeed in demonstrating what one might call (only partly tongue-in-cheek) the "resourcefulness" of the adaptationist perspective, and also do pretty well in countering current methodological and epistemological critiques of adaptationist theorizing. But their apparent reasons for making adaptation the centre of attention of a scientific study of human nature include some contentious views about evolutionary biology.

Following a long introduction to the structure and conceptual foundations of evolutionary theory (which is sound, but which could have been improved by incorporating at least some of the recent work in philosophy of biology), the authors turn their evolutionary lens upon their own kind - upon human values, cognition and language. As for values, they warn against the "naturalistic fallacy" of those who pretend to derive normative conclusions from purely evolutionary premises, but warn also against the "anti-naturalism" of those who believe that the facts of evolution are entirely irrelevant to ethics. As for cognition, they concentrate upon the "evolutionary exegesis of Kant": to what extent, they ask, are the categories of cognition grounded in neurological structures that are, in turn, the products of evolution by natural selection. They acknowledge, in this regard, some of the problems that result from "spiking" the brain with "an overly rich mixture of cognitive spirits". And, as for language, they are interested in the extent to which the individual development of grammatical skills "recapitulates"' the phylogenetic history of grammatical innovations.

Adaptationist accounts of human nature are certainly worth entertaining. But I question a number of Tennant and von Schilcher's underlying reasons for

\section{Paper crust}

Princeton University Press have re-issued in paperback The History of the Earth's Crust, edited by Robert A. Phinney, the proceedings of a conference held in 1966 which proved to be a landmark in the earth sciences. The book was first published in 1968. Price of paperback is $\$ 11.50, £ 10$. pursuing such an approach, some of which seem to me to be based on serious misrepresentations of the structure and domain of evolutionary biology. First, they misconstrue evolutionary theory as being underpinned by nothing more than principles of natural selection, and evolutionary biology as being nothing more than the study of adaptations. Then they make unjustifiably bold claims about the domain of evolutionary biology - that is, about how much we can expect to explain in terms of evolution by natural selection.

For instance, among the "components" of the modern synthetic theory of evolution they include "The postulation of natural selection working on random genetic mutations as the one and only mechanism of evolutionary change"' (p.97). And yet most versions of the HardyWeinberg law (the central principle of the synthetic theory) cite natural selection, mutation, migration, random drift and non-random mating as possible means of evolutionary change.

Even when von Schilcher and Tennant acknowledge alternative mechanisms of evolution, random drift for example, they belittle the search for such phenomena. For instance, they claim that

the pan-selectionist point of view is the only possible working hypothesis. This is simply because someone not searching for a function [i.e. adaptation] will never find one, even if one should exist [p.63].

But surely it would be just as unlikely for someone to find an instance of random drift if they were not looking for it. In other words, there may be a good reason for saying that the pan-selectionist point of

\section{Aspects of genius}

\section{R.S. Woolhouse}

Leibniz. By G. MacDonald Ross.

Oxford University Press: 1984. Pp.121. Hbk £7.95, \$12.95; pbk £1.95.

LEIBNIZ (1646-1716) was a multifaceted genius. He was archivist, diplomat, engineer, inventor, librarian, poet and politician. And his vast output of writing covered alchemy, anthropology, dynamics, economics, geology, history, jurisprudence, linguistics, logic, mathematics, numismatics, philosophy and religion.

The introduction to George MacDonald Ross's clear and very readable contribution to the Past Masters series prides itself on recognizing this fact. It leads us to expect the novelty of a discussion of all aspects of Leibniz's work and thought. But, after the initial notice taken of them in the valuable account of his life, most are ignored. As usual it is Leibniz's philosophy and parts of his mathematics that really receive the attention.

As even this is a lot to cover in a limited space it need be no surprise if this short view is the only possible working hypothesis, but von Schilcher and Tennant have not provided it.

Finally, consider the authors' bold $a$ priori extension of biological evolutionary theory to cultural evolution:

A priori biological evolution is going to produce culturally adapted individuals when an important part of the environment is cultural; and genotypes placed in such environments will produce phenotypes with important cultural traits [p.113].

And they add:

to discern a causal interaction between genes and culture is not to make a category mistake; indeed, its denial is a logical contradiction once culture is reckoned to the environment, cultural traits are reckoned to the phenotype, and the core conditional of evolutionary theory is understood just as before [p.113].

I believe that the authors have seriously overestimated the power of pure reflection here, and have tried unsuccessfully to turn an empirical, scientific issue into a philosophical one.

In one sense fortunately, and in another sense unfortunately, the authors' stimulating account of the ramifications of an adaptationist approach to human nature does not entirely depend upon their having established the all-importance of evolution by natural selection. It is fortunate in that their discussions, and many of their arguments, are still well worth consideration. It is, however, unfortunate in that the needless mistakes are distracting indeed.

John Beatty is an Associate Professor of Philosophy at Arizona State University, Tempe, Arizona.

book is not without flaws. Though Leibniz indeed says otherwise, it is not true of the historical Descartes that he squared human behaviour with his law of motion-conservation by making the soul change only the direction of motion of brain particles, not the amount. And though Leibniz did question how mind could possibly act on body, this was a background metaphysical worry. It was not a particular response to an attempt to make that action consistent with believed empirical laws. His specific objection to the manoeuvre he attributed to Descartes was that though it saved Descartes's (in fact false) law of motionconservation, it did not save the (true, but unknown to Descartes) law of momentumconservation.

Yet MacDonald Ross's achievement in introducing and summarizing Leibniz is considerable. Inevitably he compresses and omits. But he does not generally resort to superficialities, or rely on vague and general gestures. As a whole the book is fresh, stimulating and very informative. $\square$

R.S. Woolhouse is Senior Lecturer in Philosophy at the University of York, and editor of Leibniz: Metaphysics and Philosophy of Science (Oxford University Press, 1981). 